\title{
High affinity of lead for fetal haemoglobin
}

\author{
C N ONG* AND W R LEE
}

From the Department of Occupational Health, University of Manchester, Manchester M13 9PT, UK

ABSTRACT In-vitro experiments using ${ }^{203} \mathrm{~Pb}$ were performed to identify lead-binding components in human haemoglobin. Sephadex A-50 ion-exchange chromatography of haemolysate showed that different types of haemoglobin had different affinities for lead. For the haemolysate from adults, lead was present in both $\mathrm{Hb} \mathrm{A}\left(\alpha_{2} \beta_{2}\right)$ and $\mathrm{Hb} \mathrm{A}\left(\alpha_{2} \delta_{2}\right)$, whereas, in the haemolysate from new-born infants, the haemoglobin of fetal origin, $\mathrm{Hb} \mathrm{F}\left(\alpha_{2} \gamma_{2}\right)$ showed a much greater affinity for ${ }^{203} \mathrm{~Pb}$ than the adult haemoglobin $\mathrm{Hb} \mathrm{A}\left(\alpha_{2} \beta_{2}\right)$, obtained from maternal blood. Analysis of the ${ }^{203} \mathrm{~Pb}$-labelled haemoglobin suggested that about $82 \%$ of ${ }^{203} \mathrm{~Pb}$ was in the globin polypeptide. Further analysis with carboxylmethyl (CM) cellulose chromatography indicated that the $\gamma$ globin of fetal origin had a higher affinity for ${ }^{203} \mathrm{~Pb}$ than the $\beta$ globin, whereas $\alpha$ globin appeared to be unimportant in lead binding. The results of the different affinities for lead of different $\mathrm{Hb}$ types are discussed with regard to the effect of lead upon haemoglobin synthesis.

Many studies have shown that lead inhibits haem and globin synthesis in vitro and in vivo. ${ }^{1}$ By contrast, the distribution of lead in the red cell has received little attention. In blood the lead is associated mostly with erythrocytes and only a small amount is found in plasma. ${ }^{2}$ Classic views have suggested that the most likely sites of fixation are on the cell membrane ${ }^{3} 4$ but, recently, it has been shown that lead is bound to the cell constituents rather than to the stromal membrane. ${ }^{5}$ It was later shown that the binding of lead to the erythrocyte was not confined to cell membranes but that over $80 \%$ of lead in the blood penetrated into the erythrocyte and was bound to intracellular components. ${ }^{2}$

Gel chromatography of haemolysate has shown that $90 \%$ of a dose of ${ }^{203} \mathrm{~Pb}$ was attached to the haemoglobin molecule. ${ }^{6}$ Study of the lead distribution with ${ }^{210} \mathrm{~Pb}$ showed that lead was attached to haemoglobin $\mathbf{A}(\mathbf{H b} \mathbf{A})$ and to haemoglobin $\mathbf{A}_{2}$ $\left(\mathrm{Hb} \mathrm{A}_{2}\right)^{7}$ while in babies with severe lead intoxication, "lead-haemoglobin" has been reported. ${ }^{8}$ We describe the use of different approaches to the study of the interaction of lead with haemoglobin of human erythrocytes in vitro.

\footnotetext{
*Present address: Department of Social Medicine and Public Health, University of Singapore, Singapore 0316.

Received 13 June 1979 Accepted 26 July 1979
}

\section{Material and methods}

Lead-203 was supplied by Medical Research Council Cyclotron Unit, Hammersmith Hospital, London. The activity of each batch was about $800 \mu \mathrm{Ci}$ with a radioactive half-life of $\mathbf{5 2}$ hours. Radioactivity was measured by using a $\mathrm{Na}(\mathrm{T} 1)$ crystal to detect the activity at $279 \mathrm{KeV}$ with a LKB-Wallace Ultragamma Counter. Blood was obtained from volunteers by venepuncture; fetal blood was obtained as cord blood from the central delivery unit, St Mary's Maternity Hospital, Manchester. Sephadex ion-exchangers A-50 and CM-50 were purchased from Pharmacia (UK) Ltd; “Analar" urea was supplied by Hopkins and Williams Co; CM-cellulose was obtained from Whatman Biochemical Co Ltd; and haemoglobin markers were obtained from Gelman Harksley Ltd for $\mathrm{Hb}$ polypeptide determination.

\section{CHROMATOGRAPHIC SEPARATION OF HAEMOGLOBIN}

Incubation of erythrocytes with ${ }^{203} \mathrm{~Pb}$ and preparation of haemoglobin were carried out as previously described. ${ }^{6}$ The ion-exchange chromatography method was modified from that described by Huisman and Dozy9 to study the binding of lead to different types of haemoglobin. Separation was carried out in a column of $60 \times 0.9 \mathrm{~cm}$. Before use the column was equilibrated overnight with $\mathrm{Tris}-\mathrm{HCl}$ buffer of $\mathrm{pH}$ about $8 \cdot 2$ at a flow rate of $15-20 \mathrm{ml} / \mathrm{h}$. 
The final column used had a height of $53 \mathrm{~cm}$. Haemoglobin containing ${ }^{203} \mathrm{~Pb}$ was dialysed overnight against the same buffer at $4^{\circ} \mathrm{C}$, and $60-80 \mathrm{mg}$ was applied carefully to the column and allowed to penetrate into the adsorbent. Elution of various $\mathrm{Hb}$ fractions was obtained with a decreasing $\mathrm{pH}$ gradient. This was achieved by connecting the column to a variable gradient device, which consists of three components, containing: (A) $100 \mathrm{ml}$ of $\mathrm{pH} 8.0$ Tris$\mathrm{HCl}$ buffer, (B) $100 \mathrm{ml}$ of $\mathrm{pH} 7.5 \mathrm{Tris}-\mathrm{HCl}$ buffer, and (C) $800 \mathrm{ml}$ of $\mathrm{pH} 7.0$ Tris- $\mathrm{HCl}$ buffer.

The flow rate of the column was kept at $14-16 \mathrm{ml} / \mathrm{h}$ by adjusting the level of the " $\mathrm{C}$ " reservoir. Fractions of about $3.6 \mathrm{ml}$ were collected. One millilitre was used for radioactivity determination and the others readjusted to $5 \mathrm{ml}$ with $\mathrm{H}_{2} \mathrm{O}$ and the absorbance measured at $415 \mathrm{~nm}$. The development of the $\mathrm{pH}$ gradient was checked by examination of the $\mathrm{pH}$ effluent in every fifth tube with a pH meter.

Haemoglobin was purified from the haemolysate by the method of Winterhatler. ${ }^{10}$

\section{PREPARATION OF GLOBIN}

Haemoglobin was converted to globin using the method described by Clegg et al. ${ }^{11}$ Twenty millilitres of $\mathrm{HCl}$-acetone solution $(3: 10, \mathrm{v} / \mathrm{v})$ were kept in a flask and immersed in a $-20^{\circ} \mathrm{C}$ cooling bath. Haemoglobin was introduced drop by drop into the flask. The mixture was vigorously stirred by a magnetic stirrer for 15 minutes. Globin was obtained by centrifuging for 10 minutes at $2500 \mathrm{rpm}$, care being taken to remove any trace of acid by washing the white precipitate three times with acetone at $-20^{\circ} \mathrm{C}$. It was then purified in diethyl-ether, dried under room temperature, and stored at $-18^{\circ} \mathrm{C}$.

\section{FRACTIONATION OF THE GLOBIN CHAIN}

Separation of the globin polypeptide chains was achieved using the method described by Clegg et al. ${ }^{11}$ This chromatographic method uses carboxylmethyl (CM) cellulose in $8 \mathrm{M}$ urea and has been described as satisfactory and is extensively used for the purpose.

The chromatography buffers were prepared fresh each day. "Analar" urea, $8 \mathrm{M}$, was filtrated through Whatman No 3 paper after being dissolved in deionised water and used directly for making ionexchange buffer.

The optimum $\mathrm{Na}^{+}$ion-gradient for a $1 \times 12 \mathrm{~cm}$ column of CM-23 was obtained by mixing $150 \mathrm{ml}$ of $8 \mathrm{M}$ urea starting buffer $\left(0.005 \mathrm{M} \mathrm{Na}_{2} \mathrm{HPO}_{4}, 0.05 \mathrm{M}\right.$ $\beta$-mercaptoethanol) $\mathrm{pH} 6.8$ with $150 \mathrm{ml}$ of $8 \mathrm{M}$ urea buffer $\left(0.04 \mathrm{M} \mathrm{Na} \mathrm{NaPO}_{4}, 0.05 \mathrm{M} \beta\right.$-mercaptoethanol) also at pH 6.8.

The dry protein containing ${ }^{203} \mathrm{~Pb}$ was dissolved in chromatography starting buffer to a concentration of $10-15 \mathrm{mg} / \mathrm{ml}$. The globin was then dialysed in a
Visking tube against a 50 -fold excess of starting buffer for two hours before chromatography.

The dialysed aliquot was applied to the equilibrated CM-cellulose column and allowed to soak in under gravity. Washing of the column with starting buffer continued for 30 minutes or until no more colour (unbound material) was eluted. The polypeptide chains were then eluted at a flow rate of 1 $\mathrm{ml} / \mathrm{min}$ by means of a linear gradient at $\mathrm{pH} 6 \cdot 8$. Fractions of about $3.6 \mathrm{ml}$ were collected at room temperature. Radioactivity in every fraction was determined and absorbancy was assayed at $280 \mathrm{~nm}$.

\section{Results}

FRACTIONATION OF ADULT HAEMOLYSATE Winterhatler's method ${ }^{10}$ of purifying haemoglobin allows only soluble haemoglobin to elute from the CM-50 column, any free groups not associated with haemoglobin being detained in the column. The results obtained from this process indicated that only $7 \%$ of labelled material was detained in the column. suggesting that most of the ${ }^{203} \mathrm{~Pb}$ was eluted with the haemoglobin molecule. The CM-50 elute was concentrated and further analysed by DEAE Sephadex A-50, elution being obtained by applying a Tris- $\mathrm{HCl}$ gradient system to the column from pH 8.1 to 7.0.

The results show that the predominant type of adult haemoglobin, $\mathrm{Hb} \mathrm{A}$, was responsible for most of the lead binding (fig 1). Some of the labelled lead, however, appeared to be attached to the $\mathrm{Hb} \mathrm{A}_{2}$, whereas no lead was detected in the $\mathrm{Hb} \mathrm{A}_{1}$ fraction.

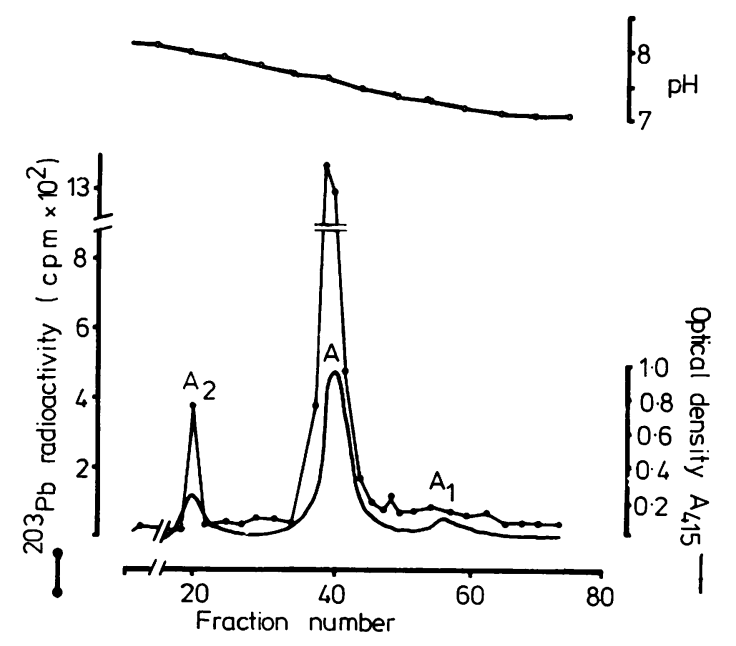

Fig 1 Separation of adult haemolysate by Sephadex A-50. 


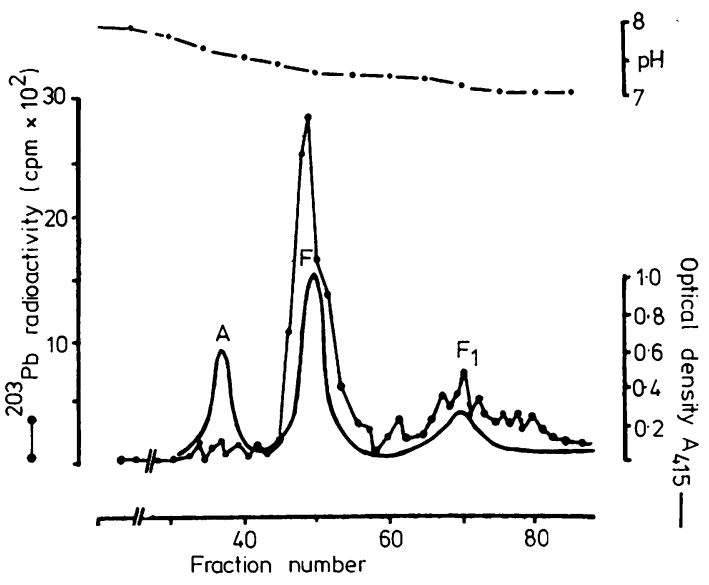

Fig 2 Separation of cord haemolysate by Sephadex A-50.

At this stage, it was not possible to decide which $\mathrm{Hb}$ type has a higher affinity for lead. It is likely that each haemoglobin may have a specific capacity to bind lead. $\mathrm{Hb} \mathrm{A}$ and $\mathrm{Hb} \mathrm{A}_{2}$ may have a higher affinity for lead than the corresponding $A_{1}$, but it is not known whether $\mathrm{Hb} \mathrm{A}$ or $\mathrm{Hb} \mathrm{A_{2 }}$ has the higher affinity for lead because the radioactivity in the fraction seems to correspond approximately to their protein concentrations.

FRACTIONATION OF CORD HAEMOLYSATE Cord blood is known to contain an additional haemoglobin, $\mathrm{Hb} \mathrm{F}$, and it is of interest to know whether the presence of this additional haemoglobin affects the binding of lead in the blood. A similar assay was carried out as performed on adult haemolysate, with a slight alteration in the $\mathrm{pH}$ gradient on ion-exchange chromatography. The ${ }^{203} \mathrm{~Pb}$ distribution pattern (fig 2 ) is clearly different from that shown in fig 1 . This was probably related to the change in the chromatographic profile. Two important features are noted. Firstly, the haemoglobin of fetal origin has incorporated almost all the lead, both $\mathrm{Hb} F$ and $\mathrm{Hb}_{\mathbf{1}}$ containing a significant amount of ${ }^{203} \mathrm{~Pb}$. Secondly, the adult haemoglobin, $\mathrm{Hb} \mathrm{A}$, which was responsible for binding most of the ${ }^{203} \mathrm{~Pb}$ in adult haemolysate (fig 1), did not appear to associate with much of the lead, accounting for only about $5 \%$ total specific activity.

FRACTIONATION OF MATERNAL

HAEMOLYSATE WITH CORD HAEMOLYSATE

To observe the interaction of lead in the presence of both maternal and infant cord blood, "competition" experiments were performed by mixing purified

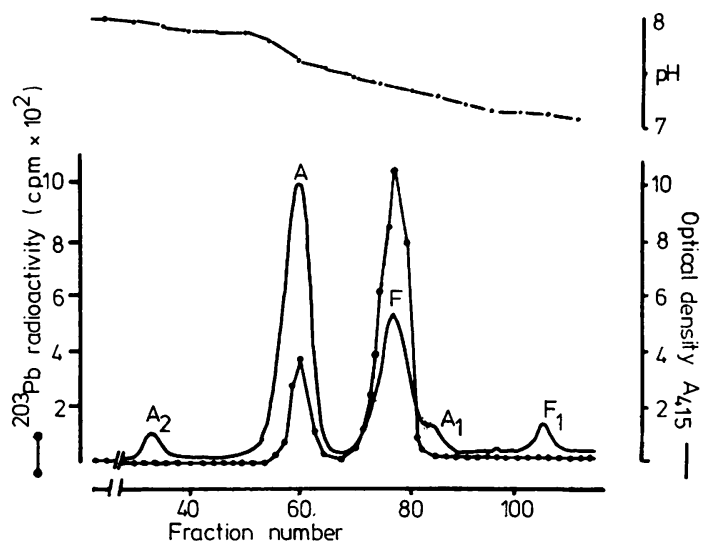

Fig 3 Separation of a mixture of maternal haemolysate with fetal haemolysate.

maternal and cord haemolysate with ${ }^{203} \mathrm{~Pb}$. Some modifications were made in the chromatographic gradient systems to achieve a fuller elution profile and four distinct but related fractions have been characterised (fig 3). Owing to the difficulty in predetermining the haemoglobin type, purified haemoglobins were applied directly for chromatographic analysis. Unfortunately, in both sets of experiments there were more adult haemoglobins and less fetal haemoglobins. This difference of haemoglobin concentration, however, did not appear to influence the experimental conclusion. In fact this discrepancy in haemoglobin concentration has made the interpretation even more direct.

The radioactivity spectrum has indicated that most of the ${ }^{203} \mathrm{~Pb}$ corresponded to haemoglobin $\mathrm{F}$. Although the adult haemoglobin, $\mathrm{Hb} \mathrm{A}$, had a higher content of protein in the fraction, it failed to bind a greater proportion of the ${ }^{203} \mathrm{~Pb}$. Haemoglobins $F_{1}$ and $\mathrm{Hb} \mathrm{A}_{2}$, which have been shown to associate with trace amounts of ${ }^{203} \mathrm{~Pb}$, were not associated with any radioactivity. It seems that the haemoglobins of fetal origin have a higher affinity for lead than the adult haemoglobin, $\mathrm{Hb} \mathrm{A}$, and that minor haemoglobin types, such as $\mathbf{H b} A_{2}$ and $\mathrm{Hb} \mathrm{F}_{1}$, have a less important role in lead binding.

\section{ASSOCIATION OF ${ }^{203}$ PB WITH GLOBIN POLYPEPTIDE CHAIN}

Globin polypeptides were extracted from haemoglobin by the method of Clegg et al. ${ }^{11}$ Over $82 \%$ of the ${ }^{203} \mathrm{~Pb}$ was found to be incorporated into the globin peptide ${ }^{12}$ indicating that lead is associated with the globin rather than the haem molecule and suggests an approach for the identification and study of the ${ }^{203} \mathrm{~Pb}$ receptors in the polypeptide chain. 


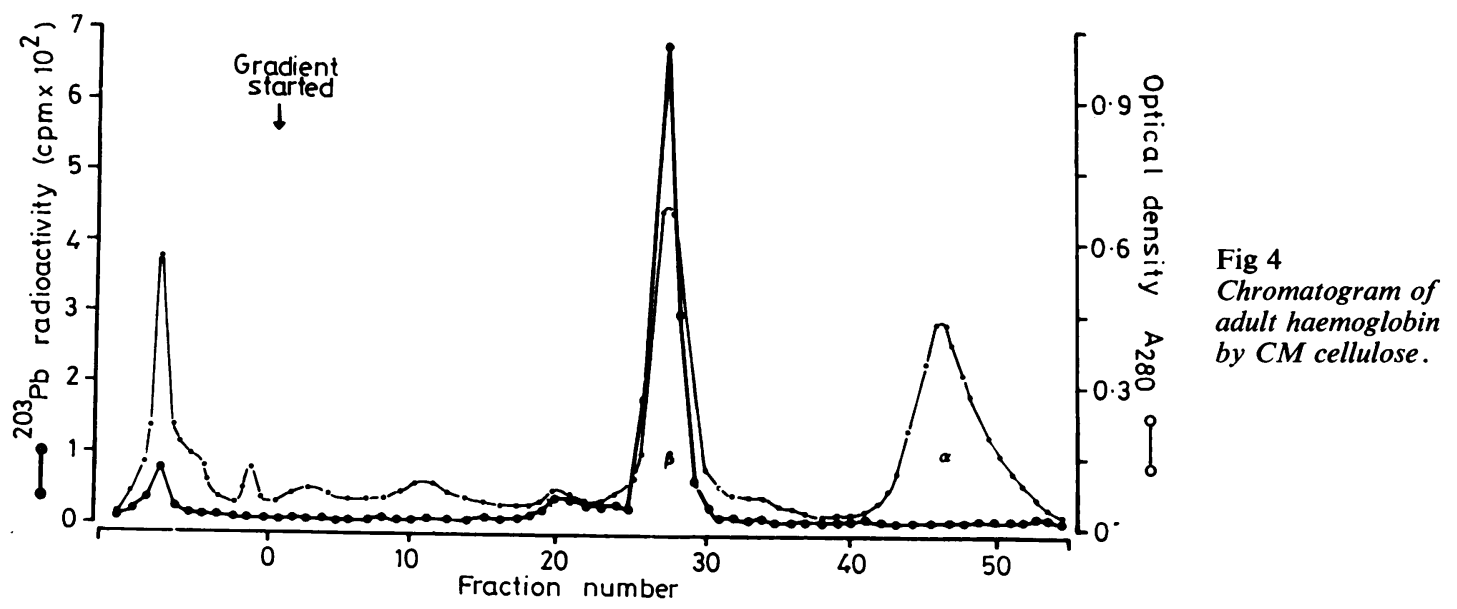

\section{Adult haemoglobin}

The chromatogram obtained from adult haemolysate pretreated with ${ }^{203} \mathrm{~Pb}$ is shown in fig 4 . Three distinct components were detected. The haem molecule was not absorbed into the column and was eluted in the forerun. The globin chains, $\beta$ and $\alpha$, derived from the adult haemoglobin, $\mathrm{Hb} \mathrm{A}$, appeared at fractions 28 and 45 , respectively. The lead distribution spectrum shows a striking difference between the specific activity of ${ }^{203} \mathrm{~Pb}$ in the $\beta$ and $\alpha$ chains. The association of the ${ }^{203} \mathrm{~Pb}$ with the $\beta$ chain but not with the $\alpha$ chain suggests two possible explanations: (1) the $\beta$ globin chain has specific binding capacity for lead but the corresponding $\alpha$ chain does not; and (2) both chains are capable of binding the ${ }^{203} \mathrm{~Pb}$ but the $\beta$ polypeptide chain is more potent in competing for the binding than the $\alpha$ chain.

\section{Fetal haemoglobin}

The chromatogram from a similar experiment on fetal haemoglobin is shown in fig 5. There are important differences when this chromatogram is compared with that of adult haemoglobin (fig 4). An additional globin chain, $\gamma$ globin, which represents the fetal polypeptide was eluted immediately before the $\beta$ chain (fraction 20). (The $\alpha$ globin together with the $\gamma$ globin formed the basic globin peptides for the fetal haemoglobin F.) The $\beta$ globin, which is of less significance in fetal haemoglobin, can be observed at the usual position, fraction 28 .

The distribution of ${ }^{203} \mathrm{~Pb}$ in the globin polypeptide has also shown several important features: (1) the major binding position is in the $\gamma$ chain of cord haemolysate instead of the $\beta$ globin of adult haemoglobin; and (2) as in the previous finding, the ${ }^{203} \mathrm{~Pb}$

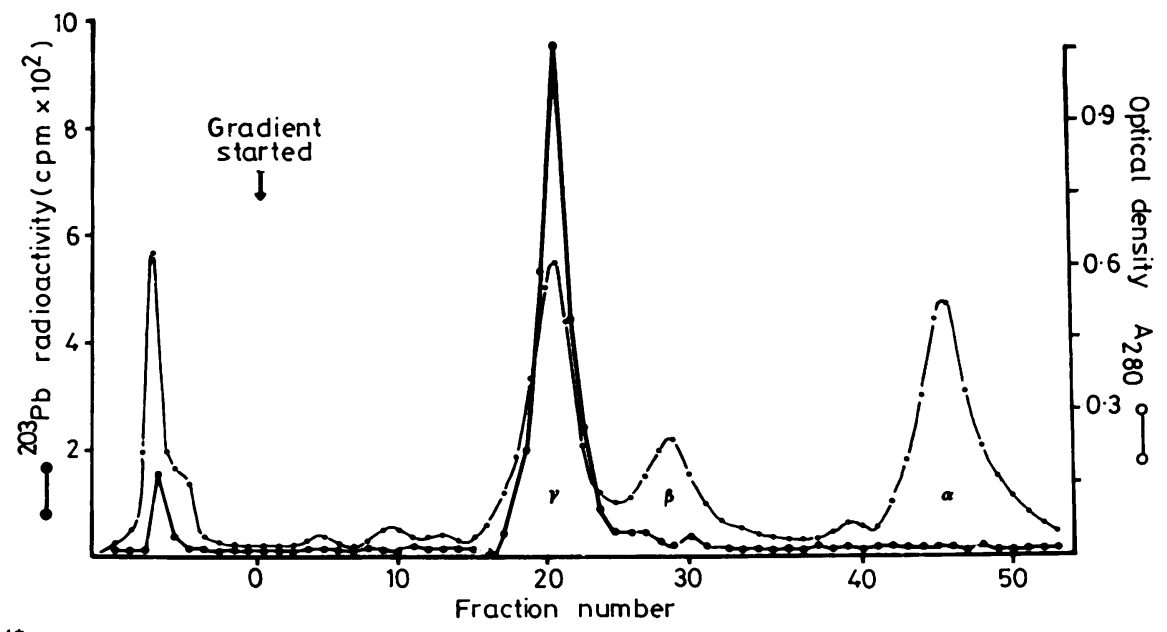

Fig 5

Chromatogram of cord haemoglobin by CM cellulose.

4* 


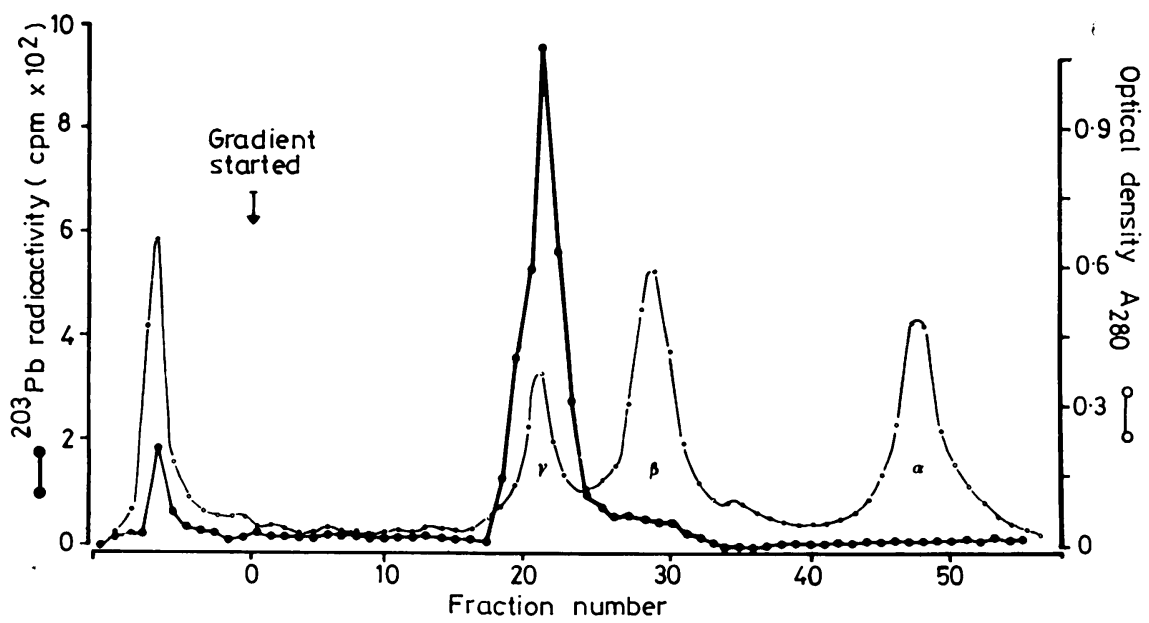

Fig 6 Separation of a mixture of maternal and infant haemoglobins by CM cellulose.

failed to link with the $\alpha$ chain. The $\beta$ chain detained virtually no ${ }^{203} \mathrm{~Pb}$ in its protein polypeptide.

\section{Mixture of fetal haemoglobin with maternal haemoglobin}

To confirm that the fetal haemoglobin is more potent in binding lead than the adult haemoglobin, a "competition assay" was carried out. Blood was collected from the cord of new-born infants and also from their mothers. After purification the haemoglobins were mixed and incubated with $15 \mu \mathrm{Ci}$ of ${ }^{203} \mathrm{~Pb}$ of ${ }^{203} \mathrm{PbCl}_{2}$ for an hour. After dialysis for six hours, globins were isolated and extracted at $-20^{\circ} \mathrm{C}$ in acid acetone. Three to five milligrams of labelled globin in buffer were applied to the CM column for ion-exchange chromatography. The chromatogram of this mixture is shown in fig 6 . Three distinct protein peaks were found in positions identical to the earlier experiments, corresponding to the $\gamma, \beta$, and $\alpha$ chains. The abundance of peptide proteins in $\alpha$ and $\beta$ chains was attributed to the contribution by both adult and fetal haemoglobins, whereas the $\gamma$ chain appeared in a lesser amount as it was contained solely in the fetal haemoglobin.

The ${ }^{203} \mathrm{~Pb}$ distribution pattern has shown: (1) The $\gamma$ chain, although containing less globin per fraction than other chains, had incorporated most of the lead. (2) Remarkably, the ${ }^{203} \mathrm{~Pb}$ bound only slightly to the adult originated chain, the $\beta$ globin. (3) Consistent with the earlier findings, virtually no ${ }^{203} \mathrm{~Pb}$ was detected in the $\alpha$ chain.

\section{Discussion}

At the present stage, that fraction of the globin molecule with which lead is associated has not been positively identified, and therefore the stoichiometric relation between lead and haemoglobin is difficult to establish. The fact that lead is able to bind preferentially with different types of haemoglobin indicates that the metal-molecule interaction may be dependent on the chemical conformation of the protein molecule.

The finding that ${ }^{203} \mathrm{~Pb}$ was attached to $\mathrm{Hb} \mathrm{A}$ and $\mathrm{Hb} \mathrm{A}_{2}$ in adult haemoglobin is consistent with the finding of Brunger et al. ${ }^{7}$ The binding of lead to both $\mathrm{Hb} \mathrm{A}$ and $\mathrm{Hb} \mathrm{A_{2 }}$ is not surprising, as there are only small changes in the globin structure of these haemoglobin molecules ( $\beta$ and $\delta$ chains differ in the position of 10 amino-acids).

Further examination of lead-binding haemoglobins (figs 4-6) has indicated that there are important differences in the affinity of lead for different globin chains. In the present studies ${ }^{203} \mathrm{~Pb}$ was never detected in the $\alpha$ globin. Therefore, it would seem that this globin is either deficient in lead receptor sites or is inferior to other globins in "competing" for the binding. The avidity of $\gamma$ chain for lead (figs 5 and 6) explained and confirmed the binding of lead to $\mathrm{Hb} \mathrm{F}$ (figs 2 and 3). Although there were slight differences in the relative affinities for ${ }^{203} \mathrm{~Pb}$ between the $\gamma$ and $\beta$ chains, in three duplicated experiments more ${ }^{203} \mathrm{~Pb}$ was found in the $\gamma$ chain than the $\beta$ chain (fig 6). Thus it may be concluded that the $\gamma$ globin of fetal haemoglobin has a pronounced affinity for lead, at least in the case of human erythrocytes.

Lead affects the erythrocytes mainly by causing increased destruction and interference with haemoglobin synthesis. While there have been many studies on the effects of lead on haem synthesis, the effect of lead on globin synthesis has received less attention. Recently, Piddington and White ${ }^{13}$ have described the defective synthesis of globin peptide in vitro caused 
by lead. A similar observation was also noted in Farkas. ${ }^{14}$ An interesting aspect of all these studies is that the $\alpha$ globin is relatively more affected than the $\beta$ globin chain.

In two cases of acute childhood poisoning it has been shown that, in addition to a significant decrease of $\alpha / \beta$ globin ratio, an extra globin appeared. ${ }^{15}$ This extra globin chain resembled $\gamma$ globin, and apparently more ${ }^{3} \mathrm{H}$-leucine was incorporated into it than into the $\alpha$ and $\beta$ chains. When the blood lead concentration fell, the " $\gamma$ " chain was missing concomitantly with increasing activity in $\alpha$ globin and $\beta$ globin synthesis, the ratio of $\alpha$ to $\beta$ globin returning to near normal. An increase of fetal type haemoglobin $(\mathrm{Hb}$ F) has been found in advanced stages of lead poisoning in man and in experimental animals. ${ }^{16} 17$ This haemoglobinopathy has also been observed by Albahary ${ }^{18}$ in workers occupationally exposed to lead. The concentration of $\mathrm{Hb} \mathrm{F}$, however, returns to normal after exposure to lead ceases. Taniguchi $e t$ al ${ }^{19}$ observed that at blood concentrations of 30 $\mu \mathrm{g} / 100 \mathrm{dl}$ or above, the erythrocyte glutathione and ALA-D showed relatively low values, and there was a significant increase in the amount of $\mathrm{Hb} F$. In the present in-vitro studies ${ }^{203} \mathrm{~Pb}$ was shown to have a high affinity for $\mathrm{Hb} \mathrm{F}$ and the $\gamma$ globin. This observation together with the above findings raise the question of whether the increase in the synthesis of haemoglobin F (particularly $\gamma$ globin) acts as a protective mechanism to cope with the increase of lead in the peripheral blood. It is tempting to suggest that some kind of regulatory mechanism of globin synthesis is in operation.

In the absence of a detailed understanding of the action of lead on globin synthesis, however, it would be unwise to try to develop an overall hypothesis to relate the increase of $\mathrm{Hb} \mathrm{F}$ in lead intoxication to the high affinity of lead to the haemoglobin. Nevertheless, the fact that lead is carried preferentially by $\gamma$ chain in haemoglobin as shown in this study coupled with the evidence as cited above, that lead may cause a reappearance of $\gamma$ chains, suggest intriguing possibilities for future work. On the other hand, different concentrations of blood lead in different individuals might just as well reflect their haemoglobin pattern as their exposure or the degree of "poisoning."

\section{Appendix}

The greater affinity of fetal haemoglobin than adult haemoglobin for lead described in this paper might provide an explanation for the findings of Waldron. ${ }^{20}$ He showed that the blood lead concentrations of preschool children living in Birmingham were higher than those of school children and suggested that the preschool children were, therefore, "more exposed."
An alternative explanation might be that the haemoglobin of the preschool children had a greater affinity for lead. In this connection it is interesting that seven of the 15 preschool children with blood lead concentrations equal to or greater than 1.6 $\mu \mathrm{mol} / \mathrm{l}$ were of Asian origin. The implications of this hypothesis for future research in haemoglobin profiles are obvious.

We thank Medical Research Council Cyclotron Unit for supplying the radioisotope, Professor A Goldberg and Dr M Moore of Stobhill Hospital, Glasgow, and Professor D J Weatherall and Dr J Clegg at the Nuffield Department of Clinical Medicine, Oxford, for their discussion and valuable help. This study formed part of the work submitted by one of us (CNO) to the University of Manchester for the degree of PhD.

\section{References}

${ }^{1}$ Goldberg A. Lead poisoning and haem biosynthesis. $B r J$ Haematol 1972;23:521-4.

${ }^{2}$ Ong CN, Lee WR. Distribution of lead -203 in human peripheral blood. Br J Ind Med 1980;37:70-7.

${ }^{3}$ Clarkson TW, Kench JE. The sedimentation rate and fragility of human erythrocytes in vitro after exposure to lead chloride. Br J Ind Med 1958;15:115-22.

${ }^{4}$ Passow HA, Rothstein A, Clarkson TW. The general pharmacology of heavy metals. Pharmacol Rev 1961;13: 185-224.

${ }^{5}$ Barltrop D, Smith A. Lead binding to human haemoglobin. Experientia 1972;28:76-7.

${ }^{6}$ Ong CN, Lee WR. Interaction of calcium and lead in human erythrocytes. Br J Ind Med 1980;37:78-84.

${ }^{7}$ Bruenger FW, Stevens W, Stover BJ. The association of $\mathrm{Pb}-210$ with constituents of erythrocytes. Health Phys $1973 ; 25: 37-42$.

${ }^{8}$ Charache S, Weatherall DJ. Fast haemoglobin in lead poisoning. Blood 1966;28:377-82.

${ }^{9}$ Huisman TH, Dozy AM. Chromatography of haemoglobin types on CM cellulose. J Chromatogr 1965;19: 160-9.

${ }^{10}$ Winterhatler KH, Heywood JD, Huehus ER, Finch CA. The free globin in human erythrocytes. Br J Haematol $1969 ; 16: 523-9$.

${ }^{11}$ Clegg JB, Naughton MA, Weatherall DJ. Abnormal human haemoglobins. J Mol Biol 1966;19:91-102.

12 Ong CN. Uptake and interaction of lead -203 with human peripheral blood in vitro. University of Manchester: 1977. (PhD thesis.)

${ }^{13}$ Piddington SK, White JM. Effects of lead on the total globin and alpha and beta chain synthesis in vitro and in vivo. Br J Haematol 1974;27:415-24.

${ }^{14}$ Farkas WR. The effects of plumbous ion on protein biosynthesis in reticulocytes. Res Commun Chem Pathol Pharmacol 1975;10:127-35.

${ }^{15}$ White JM, Harvey DR. Defective synthesis of alpha and beta globin chains in lead poisoning. Nature 1973;236: 71-3.

${ }^{16}$ de Rosnay D, Labadie P, Debot P. Recherches sur l'hamoglobine alcalinoresistance. Sa presence an cours de l'intoxication sturnine. Societe de Medicine et d'hygiene du trar. Archives des Maiadies Professionnelles de Medicine du Travail et de Securite Sociale 1957. 
17 Buckowski M. Der Einfluss der Bleivergiftung die bildung von fetalen haemoglobin. Archiv Gewerbepathol Gewerbehygiene $1964 ; 20: 537-9$.

18 Albahary C. Lead and haemopoiesis; the mechanism and consequences of the erythropathy of occupational lead poisoning. Am J Med 1972;52:367-78.
19 Taniguchi N, Sato T, Kondo T, Saito U, Takakuwa E. Carbonic anhydrase isoenzymes, haemoglobin- $F$ and glutathione levels in lead exposed workers. Clin Chim Acta 1975;59:29-38.

20 Waldron HA. Lead in the environment: preliminary communication. $J$ R Soc Med 1979;72:753-5. 